\title{
Heterotopik gastrik mukozanın sıklığı, klinik önemi ve eşlik eden diğer klinik bulgular
}

Heterotopic gastric mucosa prevalence, clinical importance and associated endoscopic findings

Nurten SAVAŞ, Enver AKBAŞ

Başkent Üniversitesi Tip Fakültesi Gastroenteroloji Bilim Dahl, Istanbul

Giriş ve Amaç: Bu retrospektif çalışmada heterotopik gastrik mukozanın sıklığ 1 , klinik önemi ve heterotopik gastrik mukozaya eşlik eden diğer endoskopik bulguların araştırılması amaçlanmıştır. Gereç ve Yöntem: 2009-2013 yılları arasında çeşitli şikayetler ile Gastroenteroloji polikliğimize başvuran ve üst gastrointestinal sistem endoskopisi yapılan 3.384 olgu çalışmaya alınmıştır. Olgulardaki heterotopik gastrik mukoza varlığı, eşlik eden diğer endoskopik bulgular, endoskopik biyopsi patoloji sonuçları ve hastaların başvuru şikayetleri değerlendirilmiştir. Bulgular: Çalışmaya alınan 3.384 olgunun 86'sinda (\%2.5) özofagusta heterotopik gastrik mukoza ile uyumlu lezyon saptanmış olup, heterotopik gastrik mukozalı hastaların 22'sinde eşlik eden reflü özofajit bulgusu (\%25.5), 7'sinde üst özofageal sfinkter disfonksiyonu (\%8.1), 10'unda hiatal herni (\%11.6), 5'inde Barrett özofagus (\%5.8), I'inde kardiya tümörü (\%1.1), l'inde (\%1.1) özofageal gastrointestinal submukozal tümör, 7’sinde (\%8.1) peptik ülser ve 74'ünde (\%86) gastrit saptanmıştır. Heterotopik gastrik mukozalı hastalarn 28 'inde (\%32.5) retrosternal yanma ve/veya regürjitasyon, 17'sinde (\%19.7) disfaji, 35'inde (\%40.6) dispeptik yakınmalar ve 6'sında (\%6.9) larengofarengeal reflü yakınmaları mevcut idi. Hastalardan alınan endoskopik antrum biyopsilerin 26'sinda (\%30) Helicobacter pylori enfeksiyonu saptanmıştır. Sonuç: Ust gastrointestinal sistem endoskopisi yapılan hastalarımızın \%2.5'inde özofagusta heterotopik gastrik mukoza saptanmış olup bu hastaların yüzde 50'si disfaji ya da reflü şikayet ile kliniğe başvuran hastalardır. Barrett özofagus sıklığ \%5.8 olarak bulunmuş olup nispeten yüksek olan bu oran heterotopik gastrik mukoza ile Barrett özofagus arasındaki ilişkiyi destekler niteliktedir.

Anahtar kelimeler: Heterotopik gastrik mukoza, gastrik inlet patch, reflü

\section{GIIRIS}

Özofagusun heterotopik gastrik mukoza (HGM)'sı diğer ismi ile inlet patch ilk olarak 1805 yllında Schmidt (1) tarafından proksimal özofagusta yerleşik ektopik gastrik mukoza için tanımlanmış klinik antitedir. Genel olarak proksimal özofagusta tanımlanmasına rağmen nadiren orta ve distal özofagusta da görülebilirler. HGM insisör dişlerden 16-21 cm uzaklıkta, üst özofageal sfinkterin hemen distalinde lateral veya posterior duvarda görülür. HGM yüzeyden hafif kabarı, yüzeyden çökük veya flat olabilir, yüzeyi düzgün veya nodüler olabilir. Makroskopik olarak somon rengi kadifemsi görünümde olup boyutları 2-3 mm'den 4.5 cm'ye kadar değişmektedir. Normal mukozadan keskin sinırlarla ayrilan tek bir parça veya multiple parçalar halinde görülebilirler (2). HGM genel
Background and Aims: In this retrospective study our aim was to find the prevalance of heterotopic gastric mucosa, evaluate its clinical importance, and study the endoscopic findings associated with heterotopic gastric mucosa in patients with diffrerent indications for gastrointestinal endoscopy. Materials and Methods: This study comprised 3.384 patients who were referred to our hospital's gastroenterology department with different complaints and to whom upper gastrointestinal endoscopy was performed during 2009-2013. Heterotopic gastric mucosa prevalance, endoscopic findings associated with heterotopic gastric mucosa, the main complaints of patients with heterotopic gastric mucosa and endoscopic biopsy findings were recorded. Results: Out of 3.384 patients, heterotopic gastric mucosa was found in 86 (2.5\%) patients. Endoscopic findings associated with heterotopic gastric mucosa was as follows: Reflux esophagitis in 22 (25.5\%) patients; lower esophageal sphincter dysfunction in 7 (8.1\%) patients; hiatal hernia in 10 (11.6\%) patients; Barrett esophagus in $5(5.8 \%)$ patients; cardiac cancer in 1 (1.1\%) patient; esophageal gastrointestinal stromal tumor in 1 (1.1\%) patient; peptic ulcer in 7 (\%8.1) patients; and gastritis in $74(86 \%)$ patients. The primary complaints of patients with heterotopic gastric mucosa included: retrosternal pain and/ or regurgitation in 28 (32.5\%) patients; dysphagia in 17(19.7\%) patients; dyspepsia in 35 (40.6\%) patients; and laryngopharengial reflux symptoms in $6(6.9 \%)$ patients. The endoscopic biopsy of antrum mucosa revealed that 26 (30\%) patients had Helicobacter pylori infection. Conclusion: Heterotopic gastric mucosa prevalance was $2.5 \%$ in our patients. Half of our patients presented with dysphagia or reflux symptoms. Barrett esophagus prevalance was $5.8 \%$, which is relatively higher, supporting the relationship between heterotopic gastric mucosa and Barrett esophagus.

Key words: Heterotopic gastric mucosa, inlet patch, reflux

olarak konjenital olarak düşünülse de, sonradan kazanılmış bir klinik olduğuna dair veriler vardır (2-4). HGM'nin tanımlanmış insidansı endoskopik çalışmalarda \%1-13.8 arasında olup otopsi çalışmalarında bu oran \%70'e dek artabilir $(3,5)$. Endoskopik olarak sıklıkla hızla özofagusa girilip veya hızla çıkıldığında HGM gözden kaçabilir ve dolayısı ile insidansı düşük olarak bulunabilir. HGM her yaş grubunda tanımlansa da en sık olarak 50'li yaşların ortalarında görülür (6). HGM hakkında epidemiyolojik veriler yetersiz olup biz de kliniğimizde HGM tanısı konan hastaların prevalansını, klinik özelliklerini ve HGM'ye eşlik eden diğer endoskopik bulgulanı retrospektif olarak değerlendirmeyi amaçladık. 


\section{GEREC VE YÖNTEM}

2009-2013 yılları arasında çeşitli şikayetler ile hastanemiz Gastroenteroloji kliniğine başvuran ve üst gastrointestinal sistem endoskopisi yapılan hastaların verileri retrospektif olarak değerlendirildi. Tüm hastalardan endoskopi işlem öncesi bilgilendirme formu okutularak yazılı onamları alındı. Sekiz saatlik açlık sonrası tüm hastalara öncelikle \%10'luk lidokainle topikal anestezi sonrası anestezi teknisyeni eşliğinde midazolam, fentanil ve propofolden oluşan premedikasyon sonrası Olympus Exera II GIF Q165 cihazı ile üst gastrointestinal sistem endoskopisi yapılmıştır. Olgulardaki HGM sıklığı ve olguların klinik özellikleri, demografik verileri HGM'ye eşlik eden endoskopik bulgular araştırılmıştır. Bütün hastalara üst gastrointestinal sistem endoskopisi deneyimli gastroenterologlar tarafından yapılmış olup bütün mukozal lezyonlar not edilmiştir. Hastalardan alınan endoskopik biyopsiler patolojik incelemeye alınmıştır. Araştırmada elde edilen verilerin istatistiksel analizleri SPSS 15.0 for Windows programı kullanılarak yapılmış olup kategorik veriler için tanımlayıcı istatistikler ortalama, yüzde ve standard deviasyon olarak verilmiştir. Bu çalışma akademik bir hastanede Helsinki Deklerasyonu Prensipleri'ne uygun olarak yapılmıştır.

\section{BULGULAR}

2009-2013 yılları arasında hastanemizde çeşitli endikasyonlarla üst gastrointestinal sistem endoskopisi yapılan yaşları 24-91 arasında değişen 3.384 olgunun 86'sında (\%2.5) özofagusta HGM ile uyumlu lezyon saptanmıştır. HGM saptanan hastaların yaş ortalaması $57.26 \pm 2.46$ olup 48'i (\%56) kadın, 38 'i (\%44) erkek hastadır. Hastaların başvuru şikayetleri Tablo l'de ve HGM'lı hastalara eşlik eden endoskopik bulgular Tablo 2'de gösterilmiştir. Tablo l'de görüldüğü üzere HGM'li hastaların 17'si (\%19.7) disfaji şikayeti ile başvurmuş olup, disfajisi olan hastaların endoskopik bulgularına bakıldığında 10'unda (\%58.8) reflü özofajit, hiatal herni, Barrett özofagus, alt özofagus sfinkter disfonksiyonu, özofageal gastrointestinal stromal tümör (GIST) biri veya birkaçı saptanmış, 7'sinde (\%41.1) ise özofagusta HGM'ye eşlik eden hiçbir endoskopik bulgu olmadığı görülmüştür. Hastaların hepsinden antrumdan endoskopik biyopsi alınmış ve 26 (\%30) hastada Helicobacter pylori (H. pylori) enfeksiyonu saptanmıştır. Özefagus

\begin{tabular}{|c|c|c|}
\hline \multirow[t]{2}{*}{ HGM'ye eşlik eden semptomlar } & \multicolumn{2}{|c|}{ HGM'li Hastalar } \\
\hline & Sayı & $\%$ \\
\hline Disfaji & 17 & 19.7 \\
\hline Retrosternal yanma, regürjitasyon & 28 & 32.5 \\
\hline Dispeptik yakınmalar & 35 & 40.6 \\
\hline Larengofarengial reflü şikayetleri & 6 & 6.9 \\
\hline
\end{tabular}

\begin{tabular}{|c|c|c|}
\hline & Sayı & $\%$ \\
\hline Reflü özefajit & 2 & 25.5 \\
\hline AÖS disfonksiyonu & 7 & 8.1 \\
\hline Hiatal herni & 10 & 11.6 \\
\hline Barrett özofagus & 5 & 5.8 \\
\hline Kardiya tümörü & 1 & 1.1 \\
\hline Özofagusta GIST & 1 & 1.1 \\
\hline Peptik ülser & 7 & 8.1 \\
\hline $\begin{array}{l}\text { Gastrit (pangastrit, } \\
\text { antral gastrit, atrofik gastrit, } \\
\text { alkalen reflü gastrit) }\end{array}$ & 74 & 86 \\
\hline
\end{tabular}

biyopsisi (HGM'den) 12 hastadan alınmış ve 8 (\%66) hastada fundal tip mukoza hücreleri saptanırken 4 (\%33) hastada antral tip mukoza hücreleri görülmüştür. Hiçbir hastada HGM biyopsisinde malignite saptanmamıştır.

\section{TARTISMA}

HGM hakkındaki epidemiyolojik veriler yetersiz olup tam prevalansı ve semptomatik vaka sıklı̆̆ belirsizdir. Bizim çalışmamızda HGM sıklığı \%2.5 olarak saptanmıştır. Ülkemizden yapılan çalışmalara bakıldığında Kekilli (7) ve arkadaşları tarafından yapılan çalışmada HGM sıklığı \%0.4 bulunurken, Akbayır (8) ve arkadaşlarının yaptığı çalışmada \% 1.67, Yüksel (9) ve arkadaşlarının yaptığı çalışmada ise HGM sıklığı \% 1.8 bulumuştur. HGM prevalansındaki bu farklılıklar HGM'nin üst özofagusta yerleşik olması, endoskopik olarak sılılkla hızla özofagusa girilip veya hızla çıkıldığında gözden kaçması veya sedasyon yapılmayan ögüren hastalarda HGM'nin gözden kaçmasına bağlanabilinir ve dolayısı ile insidansı düşük olarak bulunabilir. Bizim tüm vakalarımızda anestezi teknisyeni eşliğinde tam sedasyon sağlanmış olup HGM prevalansının nispeten yüksek çıkması buna bağlanabilir. HGM'ye eşlik eden en sık bulgular; larengofarengeal reflü (LFR), disfaji, boğaz ağrısı, globus hissi, odinofaji ve üst solunum yolları hastalıkları bulgularıdır $(5,10)$. Disfaji \%15-39 arasında değişen oranlarda görülür. Literatürde en büyük seri 487.229 vakalık bir seri olup bu seride hastaların en sık bulgularının disfaji, odinofaji, LFR bulguları ile globus olduğu gösterilmiştir (11). Bizim çalışmamızda reflü şikayetleri hastaların \%32.5'inde, reflü dışında disfaji şikayeti hastaların \% 19.7'sinde saptanmış olup reflü ve disfaji semptomları toplamda hastaların yarısında görülmüştür. Özellikle disfaji ile gelen hastaların \%40'ında endoskopik olarak HGM dışında bulgu saptanmamış olması disfaji şikayeti ile başvuran hastalarda HGM'nin mutlaka akılda tutulması gerektiğini ve bu nedenle üst özofagustan endoskopla girilirken hızlı geçilmemesi gerektiğini gösterir. Literatürde HGM'ye bağlı olduğu düşünülen birçok klinik antite mevcuttur; HGM'nin olduğu yerde tanımlanan trakeö- 
zofageal fistül oluşumu veya özofageal perforasyon $(12,13)$, striktür, ring ve web'e bağlı olan disfajiler HGM ile ilişkilendirilmiş olup hatta HGM'de asit üretiminin varlığı ve web ile birlikteliğinin olması nedeni ile Plummer Winson sendromu ile HGM arasında etiyolojik ilişki olabileceği iddia edilmiştir (14). HGM'nin artmış Barrettt özofagus ile olan ilişkisine ait birçok yayınlar da olup kimi yayınlarda HGM'li hastaların \%20'sinde eş zamanlı Barrettt özofagus saptanmıştır (15). Aslında Barrett özofagus HGM'den ayrı bir antite olarak tanımlanmış olup HGM'nin aksine konjenital değil sonradan kazanılmış prekanseröz lezyondur. Ancak aynı müsin kor protein ekpresyonu ve sitokeratin paternini göstermeleri nedeni ile her iki hastalık arasında patojenetik ilişki olduğu düşünülmektedir $(16,17)$, bununla birlikte Barrett özofagusun immatür multipotent kök hücrelerden gelişmesine rağmen HGM'nin embriyonik gastrik mukoza hücrelerinden geliştiğini belirten aksi görüş belirten yayınlar da mevcuttur (18). Bizim çalışmamızda HGM'li hastaların \%5.8'inde Barrettt özofagus, \%1.1'inde kardiya tümörü ve \%1.1'inde özofagusta gastrointestinal stromal tümör saptanmıştır. Türkiye'de gastroözofageal reflü hastalığı olan bireylerde Barrettt özofagus sıklığı gelişmiş ülkelerden daha düşük oranda (\%2) olmasına rağmen (19), bizim hasta grubumuzda Barrettt özofagus siklığının daha fazla görülmesi HGM ile Barrettt özofagus arasında olan muhtemel patojenik ilişkinin varlığını destekler niteliktedir. H. pylori HGM'li hastalarm \%19-82'sinde saptanabilmekte olup, H. pylori enfeksiyonun oral yolla bulaştı̆g göz önüne alınırsa HGM'nin proksimal yerleşimi nedeni ile H. pylori enfeksiyonu için önemli yerleşim yerlerinden biri olarak kabul edilebilinir (20). Bizim olgularımızın \%30'unda H. pylori enfeksiyonu saptanmış olup bu oran düşük gibi gö-

\section{KAYNAKLAR}

1. Schmidt FA. De Mammalian Esophago atque Ventriculo [inaugural dissertation]. Halle, in off, Batheana;1805. Cited by Truong LD, Stroehlein JR, Mc Kechnie JC. Gastric heterotopia of the proximal esophagus and review of literature. Am J Gastroenterol 1986;81:1162-6.

2. Chong Heng V. Clinical significance of heterotopic gastric mucosal patch of the proximal esophagus. World J Gastroenterol 2013;19:331-8.

3. von Rahden BH, Stein HJ, Becker K, et al. Heterotopik gastric mucosa of the esophagus: Am J Gastroenterol 2004 ;99:543-51.

4. Meining A, Bajbouj M. Erupted cysts in the cervical esophagus result in gastric inlet patches. Gastrointest Endosc 2010;72:603-5.

5. Ohara M. Incidence of heterotopic gastric mucosa in the upper esophagus in the first time narrow banding image endoscopy of consecutive 900 patients. Gastrointest Endosc 2010;71:316-7.

6. Chong VH. Heterotopic gastric mucosal patch of the proximal esophagus. In: Pascu O (Ed). Gastrointestinal Endoscopy. Crotia: In Tech Publishing, 2011:125-48

7. Kekilli M, Sayılır M, Yeşil Y, et al. Servikal özofagustaki HGM'nın endoskopik sıklığı; bir referans merkez çalışması. Akademik Gastroenteroloji 2009;8:119-22

8. Akbayır N, Alkim C, Erdem L, et al. Heterotopic gastric mucosa in the servical esophagus (inlet patch): endoscopic prevalence, histological and clinical characteristics. J Gastroenterol Hepatol 2004;19:891-6. rünse de HGM saptanan hastaların daha önceden $H$. pylori eradikasyon tedavisi alıp almadıkları bilinmediği için muhtemel olarak hastaların geçmişte kullanmış oldukları antibiyotik veya $H$. pylori eradikasyon tedavilerinin bu çalışmadaki düşük H. pylori prevalansından sorumlu olduğu olduğu kanatine varılmıştır. HGM'de en sık görülen histolojik tip kardiya veya oksintik tip mukoza olup bunu antral mukoza takip eder, bunun dişında HGM'de histolojik olarak maligniteler veya benign değişiklikler oldukça nadir olup kronik inflamasyon, atrofi, intestinal metaplazi ve displazi erişkinlerde tanımlanmış değişikliklerdir. Bizim çalışmamızda özofagustan biyopsi alınan hastaların \%66'sının kardiya tipi mukoza saptanmış ancak HGM dokusunda malignite gösterilmemiştir. Sadece 1 olgumuzda kardiya tümörü ve bir olguda orta özofagusta GIST saptanmıştır.

Sonuç olarak; çalışmamızda endoskopi yaptığımız hastaların \%2.5'inde HGM saptadık ve bu oran diğer yapılan çalışmalardaki HGM oranlarına göre nispeten daha yüksek olup bu yüksekliği hastayı tam sedatize edip endoskopi işlemini yapabilmemize ve böylece özofagus proksimalini daha dikkatli inceleyebilmemize bağlanabilinir. HGM saptanan hastaların yarısında disfaji veya reflü şikayetleri mevcut idi. Barrettt özefagus sıklığını ülkemizdeki diğer çalışmalarda görülen oranlara göre daha yüksek oranda saptadık ve bu da HGM ile Barrettt özofagus arasındaki ilişkiye bağlanabilinir, vakalarımızda H. pylori oranı nispeten düşük de olsa hastaların daha önceden $H$. pylori eradikasyon tedavisi alıp almadikları çalışma öncesi kaydedilmediği için bu düşük oran muhtemelen önceden kullanılmış olan antibiyotiklere bağlanabilinir.

9. Yüksel I, Usküdar O, Koklu S, et al. Inlet patch: Association with endoscopic findings in the upper gastrointestinal system. Scand J Gastroenterol 2008;43:910-4.

10. Maconi G, Pace F, Vago L, et al. Prevalence and clinical features of heterotopic gastric mucosa in the upper oesophagus. Eur J Gastroenterol Hepatol 2000;12:745-9.

11. Neumann WL, Lujan GM, Genta RM. Gastric heterotopia in the proximal oesophagus (inlet patch): Association with adenocarcinomas arising in Barrettt mucosa. Dig Liv Dis 2012;44:292-6.

12. Kohler B, Köhler G, Riemann JF. Spontaneous esophagotracheal fistula resulting fron ulcer in heterotopic gastric mucosa. Gastroenterology 1988;95:828-30

13. Sanchez-Pernaute A, HernandoF, Diez-Valladares L, et al. Heterotopic gastric mucosa in the upper esophagus ("inlet patch"): a rare cause of esophageal perforation. Am J Gastroenterol 1999;94:3047-50.

14. Weaver GA. Upper esophageal web due to a ring formed by a squamocolumnar junction with ectopic gastric mucosa (another explanation of the Paterson-Kelly, Plummer-Vinson syndrome). Dig Dis Sci 1979;24:95963.

15. Tan P, Mc Kinley MJ, Sporrer M, Kahn E. Inlet patch: prevalence, histologic type and association with esophagitis, Barrettt esophagus, and arthritis. Arch Pathol Lab Med 2004;128:444-7. 
16. Lauwers GY, Mino M, Ban S, et al. Cytokeratins 7 and 20 mucin core protein expression in esophageal cervical inlet patch. Am J Surg Pathol 2005;29:437-42.

17. Bogomoletz WV, Geboes K, Feydy P, et al. Mucin histochemistry of heterotopic gastric mucosa of the upper esophagus in adults:possible pathogenic implications. Hum Pathol 1988;19:1301-6.

18. Feurle GE, Helmstaedter V, Buehring A, et al. Distinct immunohistochemical findings in columnar epithelium of esophageal inlet patch and Barrett's esophagus. Dig Dis Sci 1990;35:86-92.
19. Bayrakci B, Kasap E, Kitapcioglu G, Bor S. Low prevalence of erosive esophagitis and Barrettt esophagus in a tertiary referral center in Turkey. Turk J Gastroenterol 2008;19:145-51.

20. Alagozlu H, Simsek Z, Unal S, et al. Is there an association between Helicobacter pylori in the inlet patch and globus sensation? World J Gastroenterol 2010;16:42-7. 